\title{
Natural convection heat transfer coefficient for newborn baby
}

\author{
Thermal manikin assessed convective heat loses
}

Ziemowit Ostrowski $^{1}$ (D) Marek Rojczyk ${ }^{1}$

Received: 30 March 2017 / Accepted: 16 October 2017 / Published online: 16 November 2017

(C) The Author(s) 2017. This article is an open access publication

\begin{abstract}
The energy balance and heat exchange for newborn baby in radiant warmer environment are considered. The present study was performed to assess the body dry heat loss from an infant in radiant warmer, using copper cast anthropomorphic thermal manikin and controlled climate chamber laboratory setup. The total body dry heat losses were measured for varying manikin surface temperatures (nine levels between $32.5^{\circ} \mathrm{C}$ and $40.1^{\circ} \mathrm{C}$ ) and ambient air temperatures (five levels between $23.5^{\circ} \mathrm{C}$ and $29.7^{\circ} \mathrm{C}$ ). Radiant heat losses were estimated based on measured climate chamber wall temperatures. After subtracting radiant part, resulting convective heat loses were compared with computed ones (based on $\mathrm{Nu}$ correlations for common geometries). Simplified geometry of newborn baby was represented as: $(a)$ single cylinder and $(b)$ weighted sum of 5 cylinders and sphere. The predicted values are significantly overestimated relative to measured ones by: $28.8 \%$ (SD 23.5\%) for (a) and 40.9\% (SD 25.2\%) for (b). This showed that use of adopted general purpose correlations for approximation of convective heat losses of newborn baby can lead to substantial errors. Hence, new Nu number correlating equation is proposed. The mean error introduced by proposed correlation was reduced to $1.4 \%$ (SD 11.97\%), i.e. no significant overestimation. The thermal manikin appears
\end{abstract}

This is an extended version of the conference contribution presented at 7th European Thermal-Sciences Conference (Eurotherm2016) [1].

Ziemowit Ostrowski ziemowit.ostrowski@polsl.pl

1 Institute of Thermal Technology, Biomedical Engineering Laboratory, Silesian University of Technology, Konarskiego, 22, 44-100 Gliwice, Poland to provide a precise method for the noninvasive assessment of thermal conditions in neonatal care.

Keywords Nu correlation · Heat transfer coefficient . Natural convection $\cdot$ Newborn baby $\cdot$ Radiant warmer

\section{Nomenclature}

$c_{p} \quad$ heat capacity, $\mathrm{J} \cdot \mathrm{kg}^{-1} \cdot \mathrm{K}^{-1}$

$D \quad$ diameter (trunk/limb/head), $\mathrm{m}$

$F_{\varepsilon} \quad$ transfer factor (radiation), -

$g \quad$ gravitational acceleration, $\mathrm{m} \cdot \mathrm{s}^{-2}$

$h \quad$ heat transfer coefficient, $\mathrm{W} \cdot \mathrm{m}^{-2} \cdot \mathrm{K}^{-1}$

$k$ thermal conductivity of fluid, $\mathrm{W} \cdot \mathrm{m}^{-1} \cdot \mathrm{K}^{-1}$

$m \quad$ mass flow rate, $\mathrm{kg} \cdot \mathrm{s}^{-1}$

$P \quad$ dry heat losses, $\mathrm{W}$

$P_{c} \quad$ convective heat losses, W

$P_{r} \quad$ radiative heat losses, $\mathrm{W}$

$S_{e} \quad$ effective body surface area, $\mathrm{m}^{2}$

$T_{a} \quad$ ambient (free-stream) temperature, $\mathrm{K}\left({ }^{\circ} \mathrm{C}\right)$

$T_{f} \quad$ film temperature $\left(T_{s}+T_{a}\right) / 2, \mathrm{~K}\left({ }^{\circ} \mathrm{C}\right)$

$T_{s} \quad$ skin (manikin) surface temperature, $\mathrm{K}\left({ }^{\circ} \mathrm{C}\right)$

$T_{w} \quad$ climte chamber wall temperature, $\mathrm{K}\left({ }^{\circ} \mathrm{C}\right)$

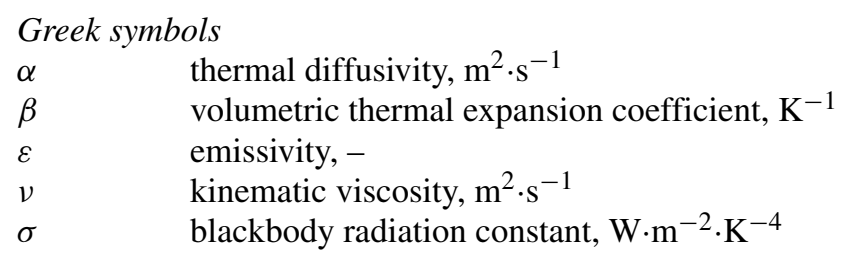

Dimensionless

$\begin{array}{ll}\mathrm{Nu}_{D} & \text { Nusselt number, } \frac{h D}{\nu^{k}} \\ \operatorname{Pr} & \text { Prandtl number, } \frac{\alpha^{\alpha}}{g \beta} \\ \operatorname{Ra}_{D} & \text { Raileigh number, } \frac{}{v \alpha}\left(T_{s}-T_{a}\right) D^{3}\end{array}$ 


\section{Introduction}

The heat exchange with the environment is of greater importance in the infant than in the adult, explaining the increased risk of body hypo- or hyperthermia [2]. As result, maintaining fluid and heat balance is of vital importance to the newborn infant [3]. The infants are exposed to a cold and dry environment, and are then at risk of dehydration and hypothermia. These conditions may have serious consequences and significantly influence mortality and morbidity.

Moreover in recent years there is a growing interest in therapeutic use of hypothermia for treatment of neonatal encephalopathy [4-7]. To assist both therapy design and control, attempts are made to use mathematical models of human thermal physiology (i.e. heat transfer and active thermoregulation) [8-12].

To take advantage of all above mentioned issues, including the therapeutic hypothermia modeling, it is important to understand and quantify the heat transfer processes between the baby and its environment whilst it is in the radiant warmer.

There are numerous studies on natural convection heat transfer coefficient in adults based on direct measurements and thermal manikins $[13,14]$, as well as based on numerical simulations [15]. Review and comparison of convective heat transfer coefficients of the adult human body in several studies is presented in [16].

However, for a case of newborn babies, the available literature sources are very limited. The only available data are obtained for newborn thermal manikins in a single-walled, air-heated closed incubators. Early reports, like [17], were based on simplified geometry manikins, while recent studies of dry heat losses from the manikin $[18,19]$ account for anthropomorphic premature newborn sized manikins. Yet, expect of initial measurements reported in [20], no detailed reports have been found for open type radiant warmers that are widely used in pediatric centers.

Due to ethical reasons, experiments cannot be performed on living infants, while they are at risk of body cooling and cannot tolerate the experimental procedures. In such situation, the idea of thermal manikins' usage for heat exchange identification arises in natural way. As result, within current research, the heated thermal manikin and controlled climate chamber setup is being proposed, designed and used to study dry heat loses in stagnant air for the infant laying in infant care bed conditions.

\section{Materials and methods}

\subsection{Thermal manikin}

The anthropomorphic thermal manikin is used in the present study to represent newborn baby. Its size correspond to the

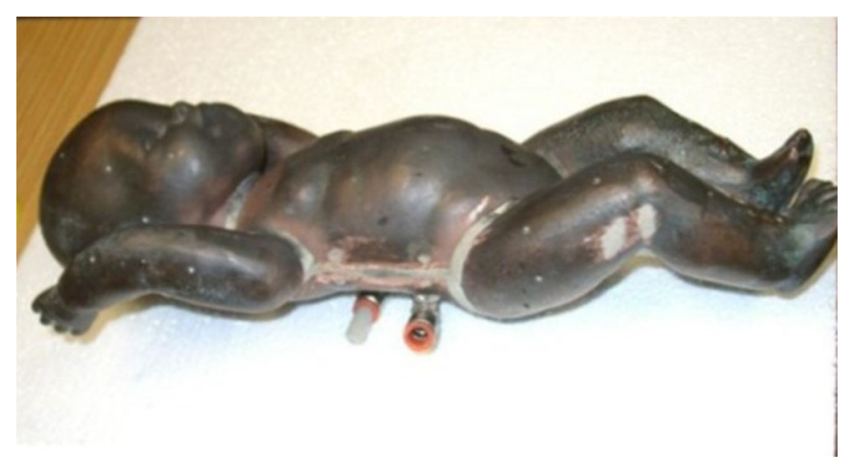

Fig. 1 Cooper cast infant anthropomorphic thermal manikin

dimensions of prematurely born baby (35 week of gestational age) in 50th percentile [21]. The manikin, shown in Fig. 1, was cast in copper and painted matt (graphite) black (see Fig. 6). The model was designed to mimic newborn baby with body surface area $S=0,13278 \mathrm{~m}^{2}$ (measured by means of 3D manikin scan). The dimensions of manikin are presented in the Table 1.

To maintain and control the constant surface temperature of the manikin, the water heating system was proposed. Stabilized $\left( \pm 0.01{ }^{\circ} \mathrm{C}\right)$ temperature water (Advanced Digital Controller Refrigerated/Heated Circulating Baths, model AD07R-40, VWR International, USA) was supplied into the thermal manikin by means of rubber hoses. To obtain uniform temperature distribution over body surface, the water inlet was divided into 5 separate outflow ports located in limbs (four) and head (one). The outlet port was located on the back of the manikin (see Fig. 2). The mass flow rate of heating water was kept on elevated level, to ensure uniform manikin surface temperature distribution. Uniform temperature distribution was achieved, an exemplary IR thermogram (ThermaCam SC2000, FLIR, USA) of body surface temperature is shown in Fig. 3, mean value of surface temperature with one standard deviation (SD) is $36.42{ }^{\circ} \mathrm{C}\left(0.13{ }^{\circ} \mathrm{C}\right)$. Slightly elevated temperature was measured only in self irradiated areas of the manikin surface (and these locations were excluded form above mentioned mean temperature computation).

Personal computer (LabView Signal Express software and 24-Bit Universal Analog Input card NI9219 National

Table 1 Thermal manikin dimensions

\begin{tabular}{lll}
\hline & Diameter, cm & Length, cm \\
\hline Head & 10.2 & - \\
Trunk & 9.2 & 18 \\
Arm & 3.8 & 16 \\
Tight & 4.8 & 18 \\
Body length & - & 46 \\
Head perimeter & - & 32
\end{tabular}




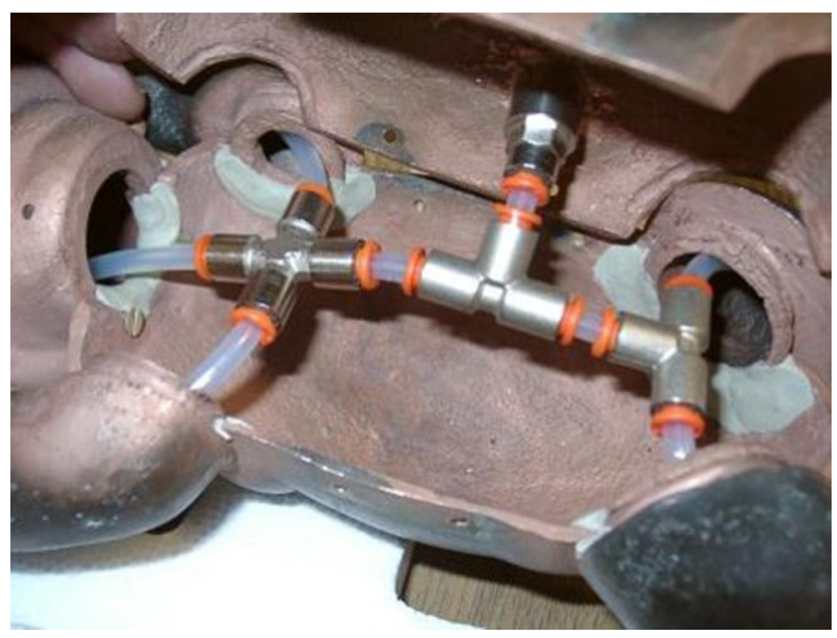

Fig. 2 Stabilized temperature water delivery system

Instruments, USA) was used to record the manikin surface temperatures and in/out water supply (thermocouples type K, diameter $0.5 \mathrm{~mm}$, CZAH-Pomiar, Poland). Manikin surface temperature was recorded by two contact thermocouples (the same type as above) attached to the manikin surface by adhesive tape and protected by aluminium foil coating to prevent its direct irradiation (see Fig. 4). First was located in anterior (front) trunk, the latter one on posterior (back) tight. The heating power delivered to the manikin

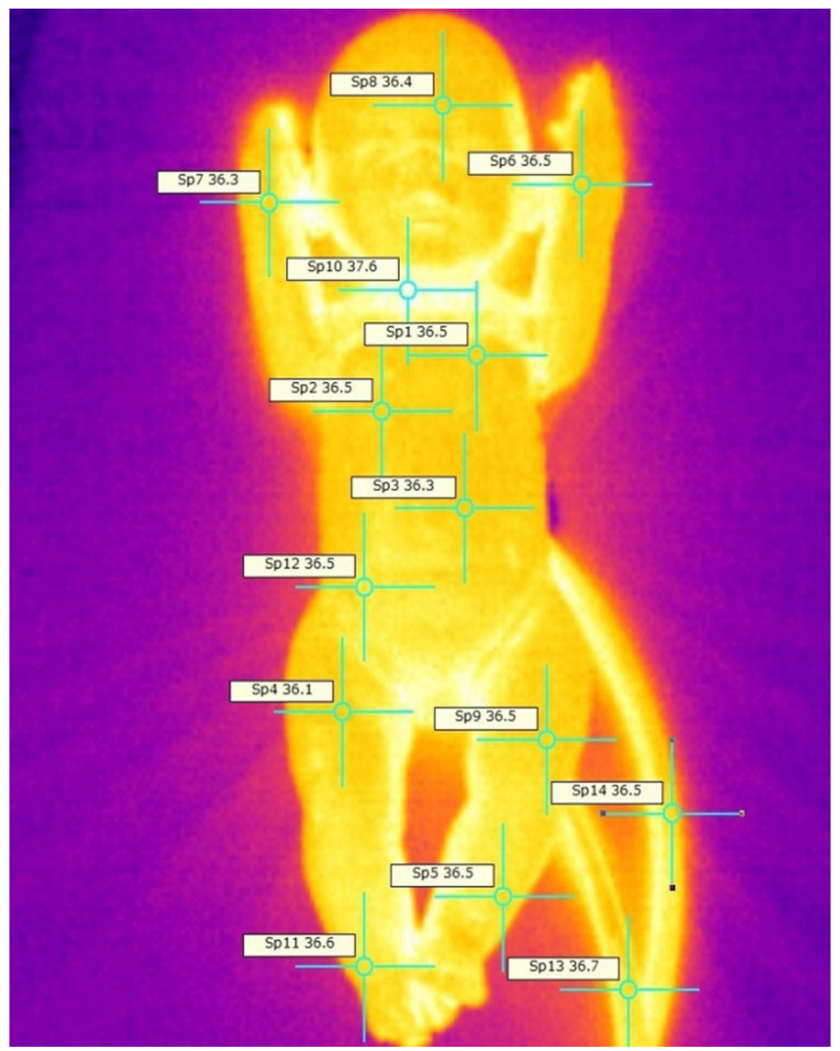

Fig. 3 exemplary IR picture of manikin surface temperature

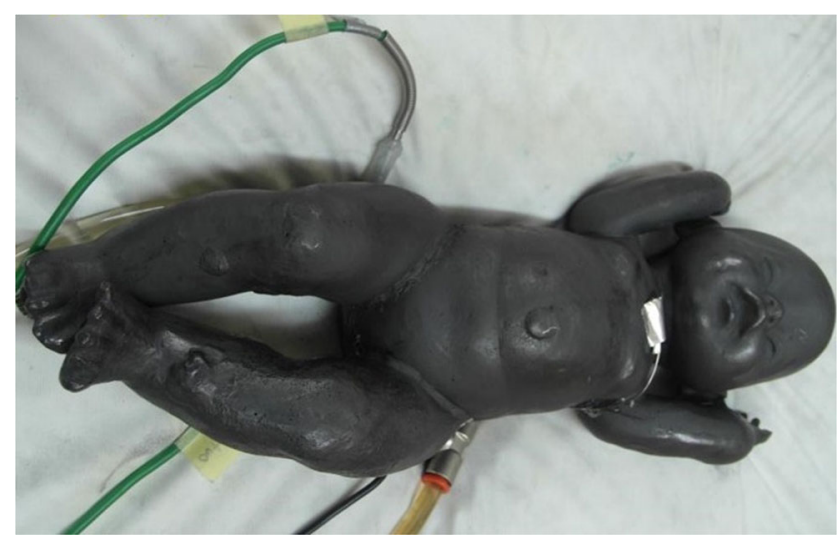

Fig. 4 Thermal manikin lying on the mattress of radiant warmer bed. Visible water ports and thermocouples measuring surface temperature (protected with aluminum foil)

(i.e. dry heat loses) was measured by means of water mass flow rate measurement (rotameter type KM, Z.A. Rotametr sp. $\mathrm{z}$ o.o., Poland) and the two thermocouples installed in inlet and outlet water ports of manikin. Therefore the heating power (i.e. dry heat loses) can be calculated as:

$P=m c_{p}\left(T_{w, \text { in }}-T_{w, \text { out }}\right)$

where: $P$ - heating power (dry heat losses), W; $m-$ water mass flow rate, $\mathrm{kg} \cdot \mathrm{s}^{-1} ; c_{p}$ - water heat capacity, $\mathrm{J} \cdot \mathrm{kg}^{-1} \cdot \mathrm{K}^{-1} ; T_{w, \text { in }}, T_{w, \text { out }}-$ thermal manikin inlet and outlet water temperatures, respectively, ${ }^{\circ} \mathrm{C}$.

\subsection{Climate chamber}

The measurements were performed in the double wall (chamber-in-chamber type) climate chamber located in the Laboratory Hall of Department of Heating, Ventilation and Dust Removal Technology (Silesian University of Technology, Gliwice, Poland). The climate chamber was made of wooden oriented strand boards (OSB), having inside dimensions: length $334 \mathrm{~cm}$, width $232 \mathrm{~cm}$ and height $220 \mathrm{~cm}$. The internal wooden chamber is located in slightly larger room, with thermal insulated walls.

Central air conditioning system was used to deliver stabilized temperature air both to in- and outside zone of the chamber. The inside air inflow is provided by means of holes in ceiling panels made of stainless steel, while four air outflow ports are located in corners (floor level). Such setup allows to control precisely the climate chamber wall temperature (by means of circulating air on both sides of chamber wall). There were 45 temperature sensors (Programmable Resolution 1-Wire Digital Thermometer, type 18B20, Maxim Integrated, USA) installed inside the climate chamber to continuous monitor and record both wall and air temperatures. Sensors were located in 11 locations, in 


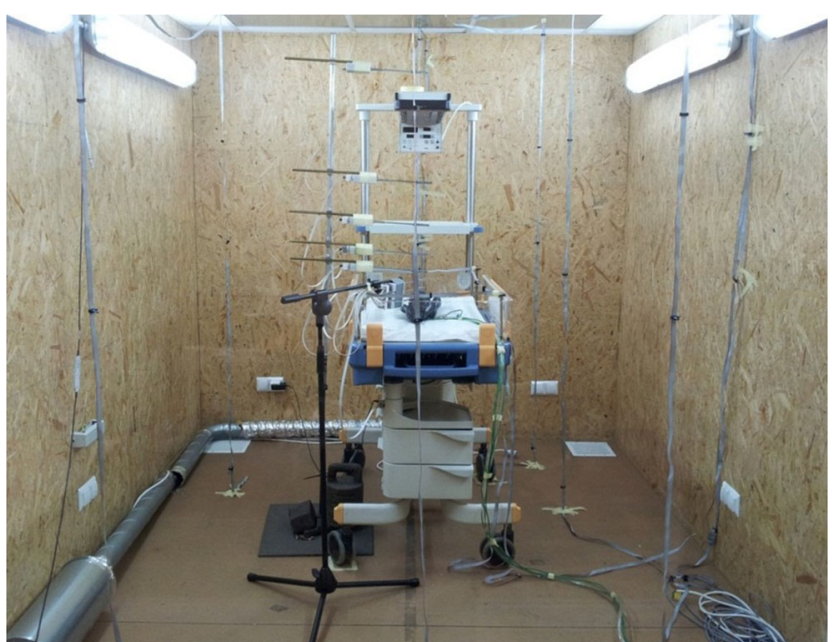

Fig. 5 Laboratory setup and equipment - thermal manikin (central) lying on the mattress of infant care bed inside the climate chamber

each location temperature was measured in 4 levels: $10 \mathrm{~cm}$, $110 \mathrm{~cm}, 160 \mathrm{~cm}$ and $210 \mathrm{~cm}$ above the floor.

Air velocity inside the climate chamber was monitored by means of omnidirectional (spherical) air speed (magnitude of velocity vector) sensors (AirDistSys 5000, Sensor Electronic, Poland). Complete laboratory setup is shown in the Fig. 5.

\subsection{Radiant warmer}

The manikin was lying in a spread-supine (with hands heading up) position on a mattress in an infant care bed (Babytherm 8000, Dräger Medical, Germany). Built in radiant warmer was set off. The mattress was not heated, and in current research can be treated as thermal insulation. Under this assumption (i.e. no conductive heat losses on the manikin - mattress interface), the body surface area used in further computations should be corrected. The manikin surface being in contact with mattress has been marked and measured (3D scan). The effective body surface area was measured $S_{e}=0.107 \mathrm{~m}^{2}$.

\section{Measurements}

During each experimental session, steady state was strictly required. First, for given air temperature and lowest surface (manikin) temperature, the steady state was reached (after approximately 4 hours), then the air flow inside the climate chamber was turned off. When the heat transfer between thermal manikin and thermal environment reached equilibrium (after approx. 15 minutes) the chamber air, wall temperatures, manikin surface temperature \& heat loses were recorded in steady state conditions. Then the surface

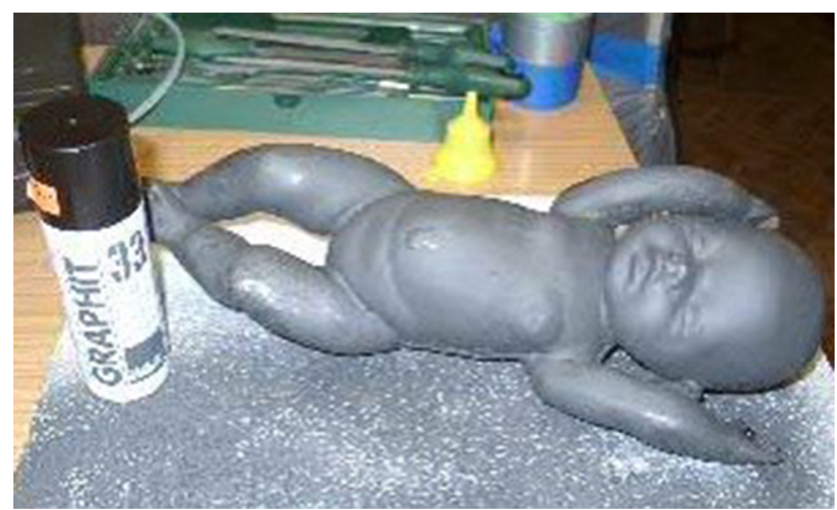

Fig. 6 Thermal manikin covered with graphite (high emissivity) spray coating

(manikin) temperature was increased up to next test case value, and after reaching equilibrium data were recorded again. Due to low dissipated power (range 4-16 W) and relatively large size of the chamber, the air temperature inside the chamber was constant during experiment, i.e. the overall air temperature increase was negligible in course of taking measurements.

The temperature measurements were recorded with $2 \mathrm{~Hz}$ frequency for every test case in steady conditions (for approx. 10 minutes each, resulting in approx. 1200 samples for every test case). Mean values of recorded: manikin surface temperatures, air \& wall temperatures and dry heat losses, calculated according to Eq. 1, are presented in Table 3. Low levels of standard deviations (SD) in recorded temperatures for all test cases confirm that the data were recorded in the steady state conditions regime, as planned.

Prior to the test sessions all temperature measurement devices (ie. thermocouples and digital sensors) has been calibrated in ice water $\left(0^{\circ} \mathrm{C}\right)$ as well as in dry-well calibration device (Transcat 5853T/model 9100S, Hart Scientific, USA). Device specific offsets has been set accordingly.

During data recording sessions there were almost no vertical temperature gradients inside the chamber (within $\pm 0.1^{\circ} \mathrm{C}$ ). Air velocity was kept far below $0.1 \mathrm{~m} / \mathrm{s}$.

To account for radiative heat loses, emissivity of all surfaces exchanging heat by radiation have to be determined. The thermal manikin surface has been covered with graphite high emissivity spray coating (see Fig. 6), with known emissivity of 0.99 . Remaining surfaces data has obtained from manufacturers' datasheets, and are all listed in Table 2.

\section{Results}

The measurements were carried out under steady state conditions. The manikin was exposed to five different ambient air temperatures (between $23.5^{\circ} \mathrm{C}$ and $29.7^{\circ} \mathrm{C}$ ) and nine 
Table 2 Emissivities of the surfaces

\begin{tabular}{ll}
\hline Surface & $\varepsilon$ \\
\hline Wooden oriented strand boards (OSB) & 0.92 \\
Manikin surface (graphite spray coating) & 0.99 \\
Stainless Steel (air inflow panels in chamber) & 0.20 \\
\hline
\end{tabular}

different manikin surface temperatures (between $32.5{ }^{\circ} \mathrm{C}$ and $40.1^{\circ} \mathrm{C}$ ). Recorded temperatures and dissipated dry heat loses, calculated using Eq. 1, for all test cases are listed in Table 3.

\subsection{Dry heat loses}

Similar to the observations reported in [18] for single walled, air-heated closed incubator, the dissipated power in current experiment increases linearly with the increasing excess temperature of the manikin surface over ambient air (cf. Fig. 7):

$P^{\mathrm{fit}}=0.9662\left(T_{s}-T_{a}\right)+0.4531 \quad\left(r^{2}=0.9852\right)$

\subsection{Convective heat loses}

In order to estimate pure convective heat loses, the radiation part of the manikin heat balance should be estimated first. The radiative part of total dissipated heat flux $\left(P_{r}\right)$ is computed as:

$P_{r}=S_{e} \sigma F_{\varepsilon}\left(T_{s}^{4}-T_{w}^{4}\right)$

where: $S_{e}$ - effective body surface area, $\mathrm{m}^{2}, \sigma=5.67 \times 10^{8}$, $\mathrm{W} \cdot \mathrm{m}^{-2} \cdot \mathrm{K}^{-4}$ - blackbody radiation constant; $F_{\varepsilon}$ - transfer factor (to account geometrical view factors for radiative heat exchange between manikin and surrounding), $T_{s}$ and $T_{w}$ are manikin surface and chamber wall temperatures, respectively, $\mathrm{K}$.

Convective only heat loses $P_{c}$ are then computed by subtracting radiative heat losses $P_{r}$ (2) from total dry heat losses $P(1)$ :

$P_{c}=P-P_{r}$

\subsection{Comparison with available correlating equations}

Measured convective heat loses $P_{c}$ (3) are compared with computed ones and are shown in Fig. 8. Computed values are based on general purpose (GP) Nusselt $(\mathrm{Nu})$ correlating formulas for common geometries in free convection regime: horizontal cylinder [23] and sphere [24] (see Appendix).
Table 3 Measurement data for all test cases (mean with one standard deviation): $T_{a}$ - ambient air temperature, $T_{w}$ - chamber wall temperature, $T_{s}$ - skin (manikin) surface temperature, $P$ - dry heat loses, $\mathrm{N}^{\mathrm{o}}$ test case \#

\begin{tabular}{|c|c|c|c|c|}
\hline $\mathrm{N}^{\mathrm{o}}$ & $T_{a},{ }^{\circ} \mathrm{C}$ & $T_{w},{ }^{\circ} \mathrm{C}$ & $T_{s},{ }^{\circ} \mathrm{C}$ & $P, W$ \\
\hline $1 \mathrm{~A}$ & & & $32.55(0.02)$ & $9.32(0.23)$ \\
\hline $1 \mathrm{~B}$ & & & $33.32(0.02)$ & $10.37(0.21)$ \\
\hline $1 \mathrm{C}$ & & & $34.12(0.02)$ & $11.15(0.24)$ \\
\hline $1 \mathrm{D}$ & & & $34.98(0.02)$ & $12.06(0.26)$ \\
\hline $1 \mathrm{E}$ & 23.48 & 23.11 & $35.74(0.03)$ & $13.06(0.22)$ \\
\hline $1 \mathrm{~F}$ & $(0.19)$ & $(0.21)$ & $36.58(0.04)$ & $13.61(0.24)$ \\
\hline $1 \mathrm{G}$ & & & $37.39(0.03)$ & $14.35(0.27)$ \\
\hline $1 \mathrm{H}$ & & & $38.20(0.03)$ & $15.29(0.28)$ \\
\hline $1 \mathrm{I}$ & & & $39.00(0.02)$ & $15.76(0.28)$ \\
\hline $2 \mathrm{~A}$ & & & $32.75(0.02)$ & $7.33(0.22)$ \\
\hline $2 \mathrm{~B}$ & & & $33.54(0.02)$ & $7.93(0.31)$ \\
\hline $2 \mathrm{C}$ & & & $34.35(0.02)$ & $8.84(0.29)$ \\
\hline $2 \mathrm{D}$ & & & $35.20(0.03)$ & $10.26(0.22)$ \\
\hline $2 \mathrm{E}$ & 25.25 & 24.87 & $36.03(0.02)$ & $10.76(0.25)$ \\
\hline $2 \mathrm{~F}$ & $(0.17)$ & $(0.22)$ & $36.83(0.02)$ & $11.49(0.26)$ \\
\hline $2 \mathrm{G}$ & & & $37.65(0.02)$ & $12.25(0.22)$ \\
\hline $2 \mathrm{H}$ & & & $38.45(0.02)$ & $12.99(0.25)$ \\
\hline $2 \mathrm{I}$ & & & $39.26(0.02)$ & $13.36(0.34)$ \\
\hline $3 \mathrm{~A}$ & & & $33.03(0.02)$ & $6.08(0.25)$ \\
\hline $3 \mathrm{~B}$ & & & $33.84(0.02)$ & $7.02(0.20)$ \\
\hline $3 \mathrm{C}$ & & & $34.62(0.02)$ & $7.80(0.24)$ \\
\hline $3 \mathrm{D}$ & & & $35.47(0.02)$ & $8.90(0.26)$ \\
\hline $3 \mathrm{E}$ & 26.90 & 26.51 & $36.27(0.02)$ & $9.19(0.20)$ \\
\hline $3 F$ & $(0.16)$ & $(0.21)$ & $37.09(0.02)$ & $10.17(0.21)$ \\
\hline $3 \mathrm{G}$ & & & $37.90(0.03)$ & $10.73(0.27)$ \\
\hline $3 \mathrm{H}$ & & & $38.69(0.02)$ & $11.59(0.25)$ \\
\hline $3 \mathrm{I}$ & & & $39.52(0.02)$ & $12.27(0.22)$ \\
\hline $4 \mathrm{~A}$ & & & $33.28(0.02)$ & $5.21(0.21)$ \\
\hline $4 B$ & & & $34.08(0.02)$ & $6.15(0.23)$ \\
\hline $4 \mathrm{C}$ & & & $34.90(0.02)$ & $6.77(0.24)$ \\
\hline $4 \mathrm{D}$ & & & $35.74(0.02)$ & $7.62(0.19)$ \\
\hline $4 \mathrm{E}$ & 28.41 & 28.04 & $36.55(0.02)$ & $8.25(0.21)$ \\
\hline $4 \mathrm{~F}$ & $(0.14)$ & $(0.19)$ & $37.36(0.03)$ & $9.05(0.25)$ \\
\hline $4 \mathrm{G}$ & & & $38.17(0.02)$ & $9.71(0.16)$ \\
\hline $4 \mathrm{H}$ & & & $38.98(0.03)$ & $10.50(0.28)$ \\
\hline $4 \mathrm{I}$ & & & $39.78(0.03)$ & $11.16(0.22)$ \\
\hline $5 \mathrm{~A}$ & & & $33.50(0.01)$ & $4.59(0.18)$ \\
\hline $5 B$ & & & $34.32(0.02)$ & $5.32(0.18)$ \\
\hline $5 \mathrm{C}$ & & & $35.16(0.01)$ & $6.07(0.20)$ \\
\hline $5 \mathrm{D}$ & & & $36.03(0.01)$ & $6.56(0.22)$ \\
\hline $5 \mathrm{E}$ & 29.74 & 29.44 & $36.84(0.02)$ & $7.37(0.20)$ \\
\hline $5 \mathrm{~F}$ & $(0.14)$ & $(0.15)$ & $37.66(0.03)$ & $8.01(0.25)$ \\
\hline $5 \mathrm{G}$ & & & $38.48(0.03)$ & $8.67(0.19)$ \\
\hline $5 \mathrm{H}$ & & & $39.28(0.03)$ & $9.42(0.25)$ \\
\hline $5 \mathrm{I}$ & & & $40.10(0.03)$ & $10.08(0.24)$ \\
\hline
\end{tabular}




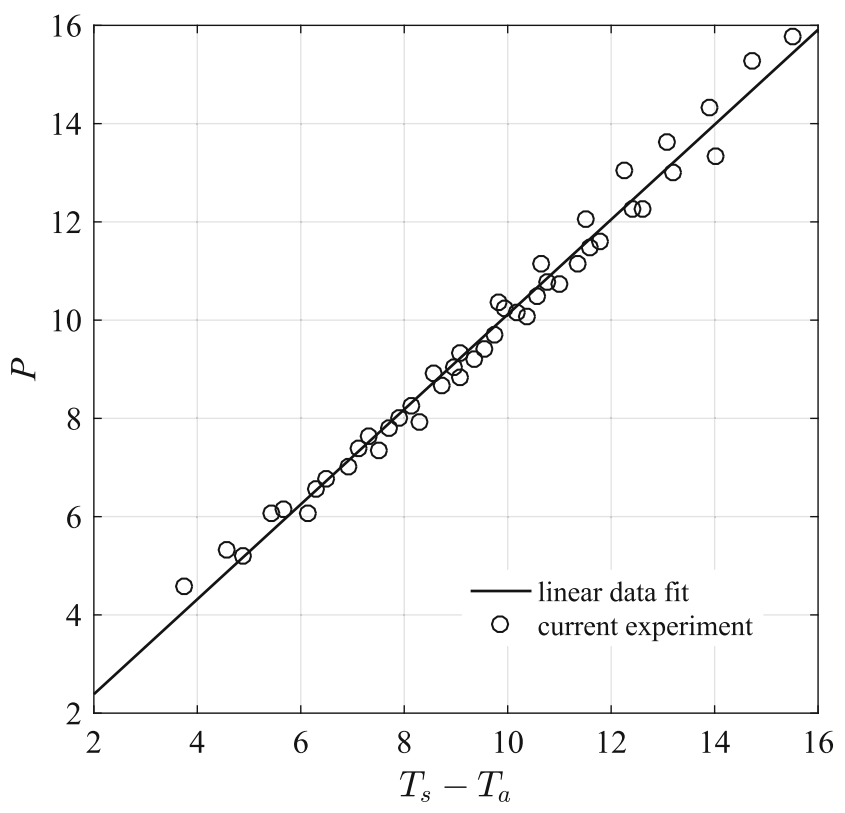

Fig. 7 Dry heat losses $(P, \mathrm{~W})$ plotted against excess temperature of the manikin surface over ambient air $\left(T_{s}-T_{a}\right)$ for current experiment. Detailed measurement data are presented in Table 3

Two cases are considered for comparison, for which convective heat transfer coefficient is estimated by means of simplified geometry of newborn baby represented as:

(a) single horizontal cylinder (with diameter as for trunk),

(b) cylinders and sphere, where the weighted sum of 5 horizontal cylinders (trunk and limbs) and sphere (head) is used to compute the overall $\mathrm{Nu}$ number. Summation weights are taken according to a Rule of nines $^{1}$, see Table 4 (the skin surface areas weights are modified in infants and children because of the proportionately larger head size).

It should be noted that the above approach assumes free (not disturbed) flow of air around modeled surfaces. In case of newborn baby in infant care bed, this assumption can not be fulfilled: newborn baby body is lying on the mattress (i.e. bottom part of the skin surface is insulated) and the presence of the infant care bed itself disturbs the air flow around the body. As result, it can be noticed that usage of classical correlating equations, valid for objects in open environment, leads to overestimation of dissipated energy. Statistical analysis t-test (MatLAB, The MathWorks, Inc., USA) shows that computed values of convective heat loses $P_{c}$ are significantly ( $p<0.001)$ overestimated relative to measured values for both approaches, by:

- $28.8 \%(23.5 \%)$ for $(a)$, and

\footnotetext{
${ }^{1}$ Rule of nines. (n.d.) 2009 Mosby's Medical Dictionary 8th edition. Retrieved March 302016 from http://medical-dictionary. thefreedictionary.com/rule+of+nines
}

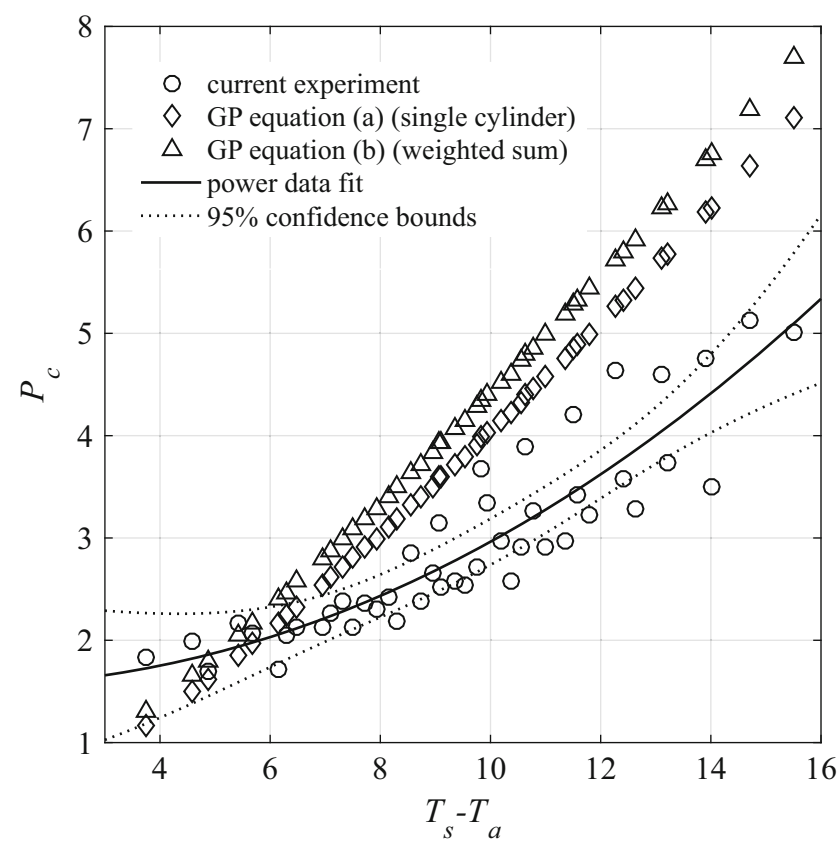

Fig. 8 Total convective heat losses $\left(P_{c}, \mathrm{~W}\right)$ plotted against excess temperature of the manikin surface over ambient air $\left(T_{s}-T_{a}\right)$, for experimental and predicted data

- $\quad 40.9 \%(25.2 \%)$ for $(b)$.

where values are presented as mean (with one standard deviation).

To overcome overestimation, the dissipated power due to convection can be approximated using two-term power series function of excess temperature of the manikin surface over ambient air (cf. Fig. 8):

$P_{c}^{\text {fit }}=0.01149\left(T_{s}-T_{a}\right)^{2.092}+1.544 \quad\left(r^{2}=0.8231\right)$

\section{Proposed correlating equation}

To generalize natural convection heat transfer coefficient estimation of the newborn baby in infant care bed the nondimensional analysis of experimental data (listed in Table 3) has been performed.

Table 4 Percentage of total body surface area for infants

\begin{tabular}{ll}
\hline & $\begin{array}{l}\% \text { of total body } \\
\text { surface area }\end{array}$ \\
\hline head & $18 \%$ \\
trunk anterior (front) & $18 \%$ \\
trunk posterior (back) & $18 \%$ \\
arm (L, R) & $9 \%$ \\
leg (L, R) & $14 \%$
\end{tabular}




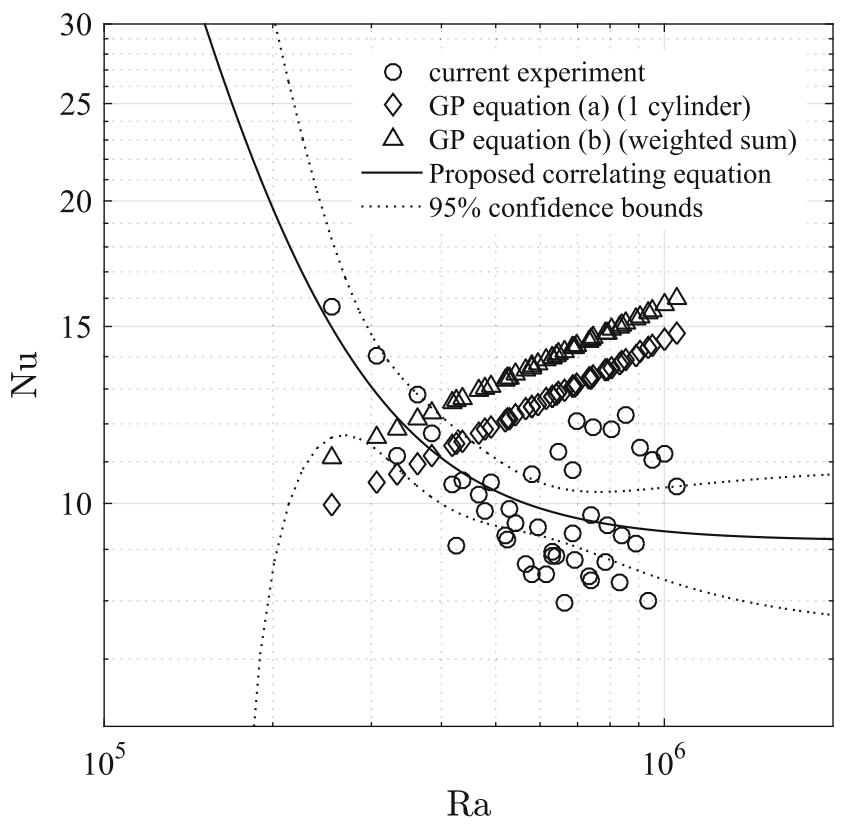

Fig. 9 Nusselt number plotted against Raileigh number for: current experiment, GP equations $(a),(b)$ and data fit (proposed correlating equation)

Air properties has been determined at film temperature (i.e arithmetic mean of surface and free stream fluid temperatures):

$T_{f}=\frac{T_{s}+T_{a}}{2}$

using CoolProp libraries [22]. The diameter of the trunk has been chosen as characteristic dimension.

Based on experimental data (in range of $2.5 \times 10^{5} \leq$ $\left.\mathrm{Ra}_{D} \leq 10^{6}\right)$ a Nusselt number $\left(\mathrm{Nu}_{D}\right)$ correlating equation for natural convection from newborn baby in air has been worked out. The two-term power series data fit $\left(r^{2}=\right.$ $0.4159)$ of $\mathrm{Nu}_{D}=f\left(\mathrm{Ra}_{D}\right)$ reads:

$\mathrm{Nu}_{D}=9.179+1.043 \times 10^{14} \mathrm{Ra}_{D}^{-2.452}$

and is shown in Fig. 9.

\subsection{Comparison of correlating equations}

The plot of proposed correlating equation is shown together with experimental data in Fig. 9. To maintain continuity, the computed values using GP equations $(a)$ and $(b)$ are shown as well.

For all test cases, the absolute error for Nu number computed using proposed correlating equation comes from a normal distribution and a zero mean (t-test, $p=0.994$ ) with SD 1.2493.

In Fig. 10 the Nu numbers determined in course of experiment are presented together with data predicted using: the proposed correlation Eq. 5 and GP correlating equations, i.e. (a) and (b).

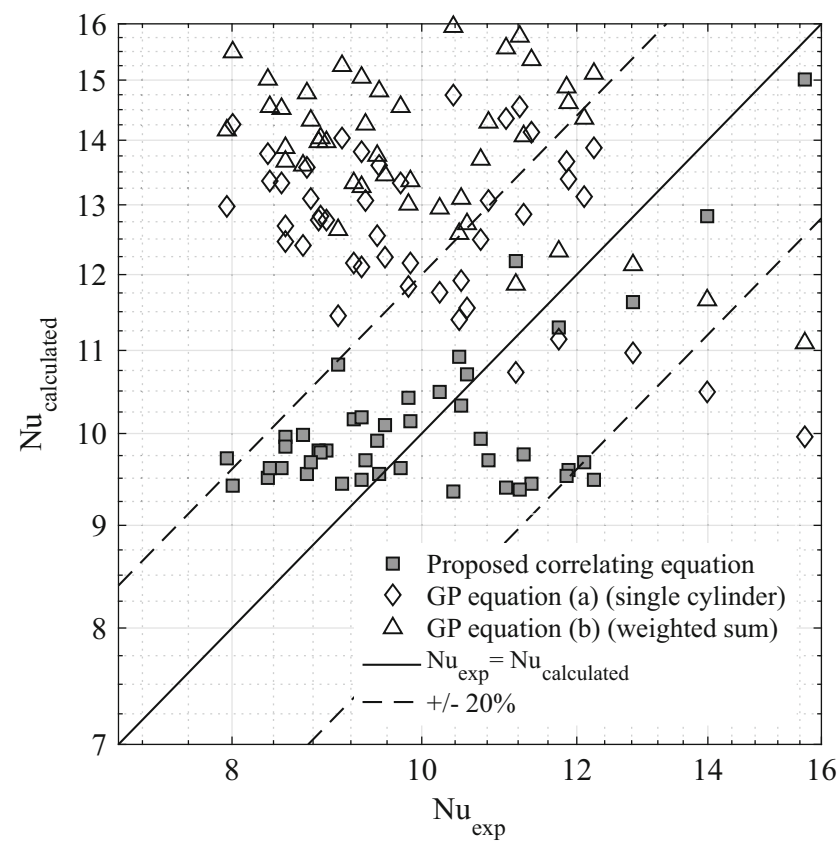

Fig. 10 Comparison of experimental Nu number with those predicted using the proposed correlation (5) and GP equations $(a)$ and $(b)$

The improvement in accuracy of convective heat losses prediction has been achieved. The computed heat loses $P_{c}$ using proposed correlating Eq. 5 is shown in Fig. 11. The mean relative error of is $1.4 \%$ (SD: $11.97 \%$ ) and what should be noticed - in contrary to errors introduced by approaches $(a)$ and $(b)$ - it shows no significant overestimation (t-test, $p=0.718)$.

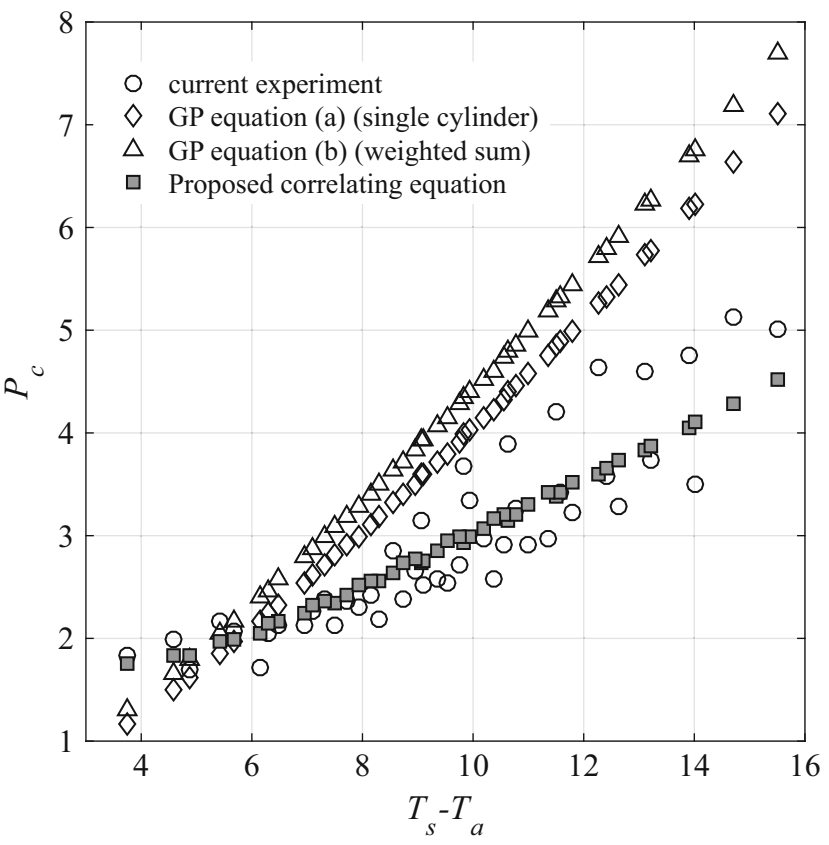

Fig. 11 Total convective heat losses $\left(P_{c}, \mathrm{~W}\right)$ plotted against excess temperature of the manikin surface over ambient air $\left(T_{s}-T_{a}\right)$ 


\section{Summary}

The anthropomorphic newborn baby thermal manikin was used to carry out measurements of the whole body dry heat loses under free convection regime in the radiant warmer-like environment. The experimental setup and proposed methodology proved to be effective way of estimating dry and convective heat loses for non-standard geometrical cases.

Presented results show that usage of general purpose $\mathrm{Nu}$ correlations leads to significant overestimation. This is due to the fact that general purpose formulas are valid for cylinders/spheres surrounded by air (with no obstructions to air flow), while in analyzed geometry, i.e. newborn baby laying on the mattress, part of the body surface is insulated and air flow is obstructed by presence of the bed itself.

Proposed correlating Eq. 5 can be used to model convective heat loses of newborn babies in real hospital conditions (radiant warmer environment) in range of ambient air temperatures $23{ }^{\circ} \mathrm{C}$ to $30{ }^{\circ} \mathrm{C}$ and skin temperatures $32{ }^{\circ} \mathrm{C}$ to $40{ }^{\circ} \mathrm{C}$. The formula has been fitted to measurements of thermal manikin which size corresponds to the prematurely (35th week) born baby, in 50th percentile [21] (see Table 1). This correspond to the Raileigh $\left(\operatorname{Ra}_{D}\right)$ number range: $2.5 \times 10^{5}$ to $10^{6}$ (trunk diameter taken as characteristic dimension). The extrapolation of the results on other newborn baby sizes has not been tested in current study.

Acknowledgements The research was supported by Faculty of Energy and Environmental Engineering, Silesian University of Technology (SUT) within Ministry of Science and Higher Education (Poland) statutory research funding scheme. We thank Dr Jan Kaczmarczyk (Department of Heating, Ventilation and Dust Removal Technology, SUT) for making a climate chamber available to the research team.

\section{Compliance with Ethical Standards}

Conflict of interests On behalf of all authors, the corresponding author states that there is no conflict of interest.

Open Access This article is distributed under the terms of the Creative Commons Attribution 4.0 International License (http:// creativecommons.org/licenses/by/4.0/), which permits unrestricted use, distribution, and reproduction in any medium, provided you give appropriate credit to the original author(s) and the source, provide a link to the Creative Commons license, and indicate if changes were made.

\section{Appendix: Correlating equations for free convection}

General purpose (GP) Nusselt $(\mathrm{Nu})$ number correlating equations for free convection regime from a:
- horizontal cylinder Churchill and Chu [23]

$$
\begin{aligned}
& \text { for } 10^{-11} \leq \operatorname{Ra}_{D} \leq 10^{9} \\
& \mathrm{Nu}_{D}^{1 / 2}=0.60+0.387\left\{\frac{\operatorname{Ra}_{D}}{\left[1+(0.559 / \mathrm{Pr})^{9 / 16}\right]^{16 / 9}}\right\}^{1 / 6}
\end{aligned}
$$

- sphere Churchill [24]

$$
\begin{aligned}
& \text { for } \mathrm{Ra}_{D} \leq 10^{11} \text { and } \mathrm{Pr} \geq 0.7 \\
& \mathrm{Nu}_{D}=2+\frac{0.589 \mathrm{Ra}_{D}^{1 / 4}}{\left[1+(0.469 / \mathrm{Pr})^{9 / 16}\right]^{4 / 9}}
\end{aligned}
$$

all properties at film temperature.

\section{References}

1. Ostrowski Z, Rojczyk M, Szczygiel I, Laszczyk J, Nowak AJ (2016) Dry heat loses of newborn baby in infant care bed: use of a thermal manikin. J Phys Conf Ser 745:032087

2. Delanaud S, Tourneux P, Ghyselen L, Le A, Bach V (2009) Heat exchanges and thermoregulation in the neonate. Arch Pediatr 16:1057-1062

3. Sedin G, Agren J (2006) Water and heat - the priority for the newborn infant. Ups J Med Sci 111:45-59

4. Edwards AD (2009) The discovery of hypothermic neural rescue therapy for perinatal hypoxic-ischemic encephalopathy. Semin Pediatr Neurol 16(4):200-206

5. Shankaran S (2009) Neonatal encephalopathy: treatment with hypothermia. J Neurotrauma 26(3):437-443

6. Rutherford M, Ramenghi L, Edwards D, Brocklehurst P, Halliday H, Levene M, Strohm B, Thoresen M, Whitelaw A, Azzopardi D (2010) Assessment of brain tissue injury after moderate hypothermia in neonates with hypoxic-ischaemic encephalopathy: a nested substudy of a randomised controlled trial. Lancet Neurol 9(1):3945

7. Schulzke SM, Rao S, Patole SKA (2007) Systematic review of cooling for neuroprotection in neonates with hypoxic ischemic encephalopathy - are we there yet? BMC Pediatr 7:30

8. Van Leeuwen GM, Hand JW, Lagendijk JJ, Azzopardi DV, Edwards D (2000) Numerical modeling of temperature distributions within the neonatal head. Pediatr Res 48(3):351-356

9. Wrobel LC, Ginalski MK, Nowak AJ, Ingham DB, Fic AM (2010) An overview of recent applications of computational modelling in neonatology philos. Trans A 368:2817-2134

10. Łaszczyk JE, Maczko A, Walas W, Nowak AJ (2014) The inverse thermal analysis of the neonatal brain cooling process. Int J Numer Method H 24(4):949-968

11. Łaszczyk JE, Nowak AJ (2015) The analysis of a newborn's brain cooling process LAP LAMBERT. Academic Publishing, Düsseldorf

12. Łaszczyk JE, Nowak AJ (2016) Computational modelling of neonate's brain cooling. Int J Numer Method H 26(2):1-23

13. Mitchel D, Wyndham CH, Vermeulen AJ, Hodgson T, Atkins AR, Hofmeyer HS (1969) Radiant and convective of nude men in dry air heat transfer. J Appl Physiol 26(1):111-118

14. Clark RP, Toy N (1975) Natural convection around the human head. J Physiol 244:283-294

15. Najjaran A (2012) Determining natural convection heat transfer coeffcientof human body. Trans Control Mech Syst 1(8):362-369 
16. Kurazumi Y, Tsuchikawa T, Ishii J, Fukagawa K, Yamato Y, Matsubara N (2008) Radiative and convective heat transfer coefficients of the human body in natural convection. Build Environ 43(12):2142-2153

17. Wheldon AE (1982) Energy balance in the newborn baby: use of a manikin to estimate radiant and convective heat loss. Phys Med Biol 27(2):285-296

18. Elabbassi EB, Belghazi K, Delanaud S, Libert J-P (2004) Dry heat loss in incubator: comparison of two premature newborn sized manikins. Eur J Appl Physiol 92(6):679-682

19. Sarman I, Bolin D, Holmér I, Tunell R (1992) Assessment of thermal conditions in neonatal care: use of a manikin of premature baby size. Am J Perinatol 9:239-246

20. Ostrowski Z, Rojczyk M, Łaszczyk J, Szczygieł I, Kaczmarczyk J, Nowak AJ (2014) Infant care bed natural convection heat transfer coefficient measurements and estimation. Przegld Elektrotechniczny 90(5):122-125

21. Fenton TR, Kim JH (2013) A systematic review and meta-analysis to revise the Fenton growth chart for preterm infants. BMC Pediatrics 13:59

22. Bell IH, Wronski J, Quoilin S, Lemort V (2014) Pure and pseudopure fluid thermophysical property evaluation and the open-source thermophysical property library CoolProp. Ind Eng Chem Res 53(6):2498-2508

23. Churchill W, Chu HHS (1975) Correlating equations for laminar and turbulent free convection from a horizontal cylinder. Int J Heat Mass Trans 18:1323-1329

24. Churchill W (1983) Free convection arround immersed bodies. In: Schlundner EU (ed) Heat Exchangesr design handbook. Hemisphere, New York. section 2.5.7 